\title{
Development of statistical methods for estimating hourly direct and diffuse solar radiation using public data for precise cultivation management
}

\author{
Hideki Ueyama ${ }^{\dagger}$ \\ Division of Hillside Horticulture Research, Western Region Agricultural Research Center, \\ National Agriculture and Food Research Organization, \\ 2575 Ikano, Zentsuji, Kagawa 765-0053, Japan
}

\begin{abstract}
High resolution data for solar radiation are particularly useful for precise cultivation management of hilly or mountainous terrains and hourly minima for both direct and diffuse solar radiation are needed to determine global solar radiation in such terrain. Estimation methods based on statistical models for determining hourly direct and diffuse solar radiation on a horizontal surface have been developed using low-cost public data. These methods use a statistical model for atmospheric transmittance. Direct solar radiation was estimated from hourly atmospheric transmittance data using a multiple regression equation with two meteorological variables, i.e., sunshine duration and extraterrestrial solar radiation on a horizontal surface. Diffuse solar radiation was estimated using a dimensionless parameter $K$ ds based on direct solar radiation, whenever sunshine duration was greater than zero. When sunshine duration was zero, diffuse solar radiation was estimated using a multiple regression equation with two other meteorological variables, i.e., precipitation and normal extraterrestrial solar radiation. The root mean square errors of estimated data for both hourly direct and diffuse solar radiation were $\sim 0.3 \mathrm{MJ} \mathrm{m}^{-2} \mathrm{~h}^{-1}$. Hourly direct and diffuse solar radiation estimated using the proposed method will be useful throughout Japan to facilitate better agricultural crop management. In addition, development of estimation methods for hourly direct and diffuse solar radiation using a numerical weather prediction model was also explored. It proved to be difficult to use estimated hourly data in the numerical model, but this numerical approach appears to be feasible for daily values.
\end{abstract}

Key words: Atmospheric transmittance, Crop management, Numerical weather prediction model

\section{Introduction}

It is important for both agricultural and ecological systems to assess solar radiation on land surfaces, especially in complex terrains having variable radiation conditions. High-resolution data for solar radiation are particularly useful for precise cultivation management of hilly or mountainous terrains, because meteorological values vary over short distances with topography (Swift and Knoerr, 1973; Cohen and Fuchs, 1987; Blennow and Persson, 1998; Kurose et al., 1999; Evans and Winterhalder,2000; Daly et al.,2007; Ueyama,2008; Holden et al.,2011). In such terrains, hourly minima for both direct and diffuse solar radiation are needed to determine global solar radiation, because shading or lighting depends on the sun's location, which varies over time. However, it is not practical or cost-effective to locate pyranometers at all sites, where solar radiation is dissimilar. Thus, estimating hourly direct and diffuse solar radiation is very important for agricultural practices in these regions.

There are a number of methods for estimating hourly direct and diffuse solar radiation levels. Some methods require global solar radiation data (Bugler,1977; Erbs et al.,1982; Watanabe et al.,1983; Flint and Childs, 1987; Reindl et al.,1990a; Michael,

Received; July 4, 2017

Accepted; October 5, 2017

†Corresponding Author: ueyama@affrc.go.jp

DOI: 10.2480/agrmet.D-17-00023
1999; Tian et al., 2001). Other methods require specific data, such as water vapor pressure, water vapor absorption, precipitable water, aerosol content, aerosol optical depth, or other satellite data (Bird and Hulstrom,1981; Gueymard,2003; Allen et al., 2006; Butt et al., 2010; Castelli et al., 2014). However, estimating solar radiation using other meteorological variables is not practical for agricultural purposes, because these are not generally available, e.g., aerosol content and water vapor pressure data. A cheaper and more convenient method is clearly needed for cultivation management, especially in hilly or mountainous agricultural areas, where yields are small.

One feasible approach is to use meteorological data acquired from nearby automated meteorological observatories, available to the public at low cost. Such data are limited, because it is hard to install and maintain instruments in an automated observatory, e.g., pyranometers and net radiometers require careful maintenance by full-time technicians. However, Ueyama (2005) developed methods to estimate both hourly direct and diffuse solar radiation on a horizontal surface, using public data from the Automated Meteorological Data Acquisition System (AMeDAS). This system includes numerous meteorological stations, which acquire hourly data throughout Japan. Around 840 stations measure temperature, wind direction, wind speed, and sunshine duration, while 1300 stations measure precipitation, and 320 stations measure snow depth. This method was augmented to make use of monthly, 10-day and 5-day mean values of these variables. Ideally, daily data would have been used, but these were scarce at the time and their accuracy on cloudy days was 
poor (Ueyama, 2008). In this study, more precise methods for estimating hourly direct and diffuse solar radiation on a horizontal surface were developed to improve the method outlined in Ueyama (2005). In addition, new estimation methods were explored, based on outputs from a numerical weather prediction model, because previous methods could not be applied to areas remote from meteorological observation sites.

\section{Theory and Methods}

\subsection{Description of original method for estimating hourly direct and diffuse solar radiation}

The daily total radiation incident on a ground surface comprises direct, diffuse, and ground reflected components. It is difficult to designate the quantity of reflected radiation, as it varies case by case. Typically, the total reflected radiation is small (Flint and Childs, 1987), and the ratio of photosynthetically active radiation to reflected radiation from a vegetation surface is also small (Kurose et al., 1999). Therefore, reflected radiation was not considered in this study. If reflected solar radiation is effective, then it is calculated using ground reflectivity and tilt angle (Reindl et al., 1990b). In this study, global solar radiation, $R_{\mathrm{g}}$ was calculated as the sum of direct and diffuse solar radiation only; while reflected solar radiation was disregarded.

Direct solar radiation, which is the flux of energy from extraterrestrial solar radiation attenuated by the atmosphere, is defined in Eq. (1); whereas atmospheric transmittance is defined in Eq. (2), after Watanabe et al. (1983).

$$
\begin{aligned}
& R_{\mathrm{b}}=R_{\mathrm{a}} \cdot \sin h \cdot \mathrm{P}^{\csc h} \\
& P=\left(\frac{R_{\mathrm{bn}}}{R_{\mathrm{a}}}\right)^{\sin h}
\end{aligned}
$$

where $R_{\mathrm{b}}$ is the hourly direct solar radiation on a horizontal surface, $R_{\mathrm{a}}$ is the hourly normal extraterrestrial solar radiation, $P$ is the hourly atmospheric transmittance, $h$ is the sun altitude angle, and $R_{\mathrm{bn}}$ is the hourly normal direct solar radiation.

Meanwhile, $R_{\mathrm{a}}$ is calculated via

$$
R_{\mathrm{a}}=\int_{T=0}^{T=1}\left(J_{\mathrm{SC}} \times d^{2}\right) d T
$$

where $T$ is the hour, $J_{\mathrm{SC}}$ is the solar constant $\left(1367 \mathrm{~W} \mathrm{~m}^{-2}\right)$, and $d$ is the ratio of the average Earth-Sun distance to its distance on a given day, calculated using the approximate formula from Shibata and Uchijima (1987) given below:

$$
\begin{aligned}
\mathrm{d}= & {[1.00011+0.034221 \cdot \cos \theta+0.0128 \cdot \sin \theta+0.000719} \\
& \cos 2 \theta+0.000077 \cdot \sin 2 \theta]^{0.5}
\end{aligned}
$$

Here, $\theta$ is determined using $\theta=2 \pi(d n-1)$, and $d n$ is the number of days elapsed since January 1 of any given year.

Ueyama (2005) proposed a multiple regression equation using three meteorological variables as an estimation model for $P$ :

$$
P=\mathrm{C}_{1} \cdot L+\mathrm{C}_{2} \cdot R+\mathrm{C}_{3} \cdot Q+\mathrm{C}_{4}
$$

where $L$ is the hourly sunshine duration (h), $R$ is the hourly precipitation $\left(\mathrm{mm} \mathrm{h}^{-1}\right), Q$ is the hourly extraterrestrial solar radiation on a horizontal surface $\left(\mathrm{MJ} \mathrm{m}^{-2} \mathrm{~h}^{-1}\right)$, and $\mathrm{C}_{1}, \mathrm{C}_{2}, \mathrm{C}_{3}$, and $\mathrm{C}_{4}$ are constants. Thus, $R_{\mathrm{b}}$ is calculated using Eq. (1), when $P$ is determined from Eq. (5) using data for $L$ and $R$.

To estimate of hourly diffuse solar radiation on a horizontal surface $\left(R_{\mathrm{d}}\right)$, values are required for both dimensionless parameters, $K_{\mathrm{d}}$ and $K_{\mathrm{s}}$, which are defined in accordance with Bugler (1977), because solar radiation fluctuates both interannually and with latitude:

$$
\begin{aligned}
K_{\mathrm{d}} & =\frac{R_{\mathrm{b}}}{R_{\mathrm{a}} \cdot \sin h} \\
K_{\mathrm{s}} & =\frac{R_{\mathrm{d}}}{R_{\mathrm{a}} \cdot \sin h}
\end{aligned}
$$

Thus, $R_{\mathrm{d}}$ is defined as:

$$
R_{\mathrm{d}}=R_{\mathrm{a}} \cdot \sin h\left(1-\frac{K_{\mathrm{d}}}{K_{\mathrm{ds}}}\right)
$$

where $K_{\mathrm{ds}}$ is the dimensionless parameter defined by Watanabe et al. (1983), as follows:

$$
K_{\mathrm{ds}}=\frac{R_{\mathrm{b}}}{R_{\mathrm{a}} \cdot \sin h-R_{\mathrm{d}}}=\frac{K_{\mathrm{d}}}{1-K_{\mathrm{s}}}
$$

Watanabe et al. (1983) determined $K_{\mathrm{ds}}$ using Eq. (10) below, where the constants $\mathrm{A}, \mathrm{B}$, and $\mathrm{C}$ are computed from observational data, using the method of linear least squares. $R_{\mathrm{d}}$ is calculated from Eq. (8), while once hourly $K_{\mathrm{ds}}$ data are acquired from Eq. (10), using $K_{\mathrm{d}}$ estimated from Eq. (6).

$$
K_{\mathrm{ds}}=K_{\mathrm{d}}+A \cdot K_{\mathrm{d}}^{B} \cdot\left(1-K_{\mathrm{d}}\right)^{C}
$$

\subsection{Estimation methods using observational data}

The method outlined in Ueyama (2005) is practical for clear days. On cloudy days, $R_{\mathrm{d}}$ is overestimated using this method, because $K_{\mathrm{d}}$ values approach zero in Eq. (8). To address this issue, two models were developed for these two sunshine conditions, related to the existence or nonexistence of L. Thus, the accuracy of the $P$ model is improved, because it only uses data, when direct sunshine exists; in this case, precipitation data is not used. In the new estimation method, direct solar radiation is assumed to be zero and $R_{\mathrm{d}}$ is estimated directly, when $L$ is zero.

However, $P$ is needed, when $L$ is non-zero; in this case, it is estimated from Eq. (11), because precipitation is close to zero:

$$
P=\alpha \cdot L+\beta \cdot Q+\gamma
$$

where $\alpha, \beta$, and $\gamma$ are constants.

$R_{\mathrm{b}}$ is calculated from Eq. (1) using a $P$ value obtained from Eq. (11), when $L$ exceeds zero.

Similarly, $R_{\mathrm{d}}$ is calculated using Eq. (8) with a $K_{\mathrm{ds}}$ value obtained from Eq. (10), when $L$ exceeds zero. In contrast, $K_{\mathrm{s}}$ values are directly estimated to acquire $R_{\mathrm{d}}$, when $L$ is zero. $K_{\mathrm{S}}$ values are influenced by the amount of $R_{\mathrm{a}}$, reflecting levels of $\mathrm{NO}_{2}, \mathrm{O}_{3}, \mathrm{H}_{2} \mathrm{O}$ and particulate aerosols; as well as the atmospheric thickness through which the solar radiation penetrates. Typically, atmospheric composition (except for $\mathrm{H}_{2} \mathrm{O}$ ) and aerosol content can be specified for a given region; hence, the effects of atmospheric composition and aerosols are included as coeffi- 
cients in the statistical model. Ueyama (2005) proposed that atmospheric thickness is related to $Q$. Meanwhile, air temperature can be related to water vapor, which influences scattered radiation, and may be related to $K_{\mathrm{s}}$. Air temperature is not useful for estimating $K_{\mathrm{s}}$, because it is highly localized and varies with topography. Moreover, Ueyama (2005) reported that adding air temperature as a variable to the estimation model for atmospheric transmittance did not improve its accuracy. Although the amount of cloud cover is related to the ratio of diffuse solar radiation to global solar radiation (Butt et al.,2010), it is not feasible to add cloud data to an estimation model for $K_{\mathrm{s}}$, because cloud cover is often nearly $100 \%$, when $L$ is zero. Instead, four meteorological factors are used as variables in a $K_{\mathrm{s}}$ estimation model: $R \mathrm{a}, Q$, sin $h$, and $R$. All these factors were found to be statistically significant in a stepwise-regression analysis, where the type 1 error (i.e., the error of rejecting the null hypothesis, when it is correct, as calculated in the SAS software) was selected to be less than 0.01 . F-values, partial regression coefficients of determination, and significance levels for these factors are shown in Table 1. The partial regression coefficients of determination for both $Q$ and $\sin h$ are smaller than for other variables. In fact, $Q$ has multicollinearity with $R_{\mathrm{a}}$, and the smallest F-value. Thus, the adjusted coefficient of determination $\left(* \mathrm{R}^{2}\right)$ was small, when sun altitude was used as a variable in the estimation model; $* \mathrm{R}^{2}$ changed from 0.39 to 0.40 , and the root mean square error (RMSE) from 0.089 to 0.081 .

Hence, $K_{\mathrm{s}}$ was estimated using:

$$
K_{\mathrm{s}}=a \cdot R+b \cdot R_{\mathrm{a}}+c
$$

where $\mathrm{a}, \mathrm{b}$, and $\mathrm{c}$ are constants.

$R_{\mathrm{d}}$ was calculated from Eq. (7), using a $K_{\mathrm{S}}$ value obtained from Eq. (12), when $L$ was zero.

\subsection{Estimation methods using output from a numerical weather prediction model}

In this method, atmospheric transmittance is required to calculate $R_{\mathrm{b}}$. Cloud amount $(C L)$ in Eq. (11) was substituted for $L$ in the mesoscale model (MSM) - the numerical weather prediction model of the Japan Meteorological Agency (JMA). Relative humidity $(R H)$ was used in the estimation model for atmospheric transmittance, because it is not site-specific data but regional data. In this case, $Q$ was not selected for a stepwise regression using $R H, R_{\mathrm{a}}$, and $C L$ as variables. This is because MSM outputs are not data points, but gridded averages. Thus, the estimation model for atmospheric transmittance $(G P)$, based on numerical model outputs, comprises $R_{\mathrm{a}}, R H$, and $C L$, as follows:

$$
G P=G_{\alpha} \cdot R_{\mathrm{a}}+G_{\beta} \cdot R H+G_{\gamma} \cdot C L+G_{\delta}
$$

where $G_{\alpha}, G_{\beta}, G_{\gamma}$, and $G_{\delta}$ are constants.

In this method, two models for $R_{\mathrm{d}}$ were used for two different $G P$ conditions, i.e., for zero or non-zero cases; this is because $L$ data are not obtained from MSM outputs. The dimensionless parameter $\mathrm{G} K_{\mathrm{ds}}$ for $R_{\mathrm{d}}$ was calculated, using an equation similar to Eq. (10), when $G P$ was non-zero:

$$
G K_{\mathrm{ds}}=G K_{\mathrm{d}}+G_{\mathrm{A}} \cdot G K_{\mathrm{d}}^{G_{\mathrm{B}}} \cdot\left(1-G K_{\mathrm{d}}\right)^{G_{\mathrm{C}}}
$$

where $\mathrm{G} K_{\mathrm{d}}$ is a dimensionless parameter of $R_{\mathrm{b}}$, calculated from Eq. (1) using $G P$.

In contrast, $K_{\mathrm{s}}$ is required to estimate $R_{\mathrm{d}}$, when $G P$ is zero. In this case, an estimation model for $K_{\mathrm{s}}$, using $\mathrm{G} K_{\mathrm{s}}$ was used to calculate $R_{\mathrm{d}}$. The $R$ in Eq. (12) was substituted for $R H$, because the reliability of $R H$ is better than precipitation data in MSM outputs. Figure 1 shows the annual relationship between observation data for 2010 and MSM outputs for hourly precipitation and $R H$ at the Shionomisaki Observatory. Data cover the time interval from 10:00 to 15:00 Japan Standard Time (JST). Thus, the $\mathrm{G} K_{\mathrm{s}}$ model comprises $R_{\mathrm{a}}$ and $R H$, as follows:

$$
G K_{\mathrm{s}}=G_{\mathrm{a}} \cdot R H+G_{\mathrm{b}} \cdot R_{\mathrm{a}}+G_{\mathrm{c}}
$$

where $G_{\mathrm{a}}, G_{\mathrm{b}}$, and $G_{\mathrm{c}}$ are constants.
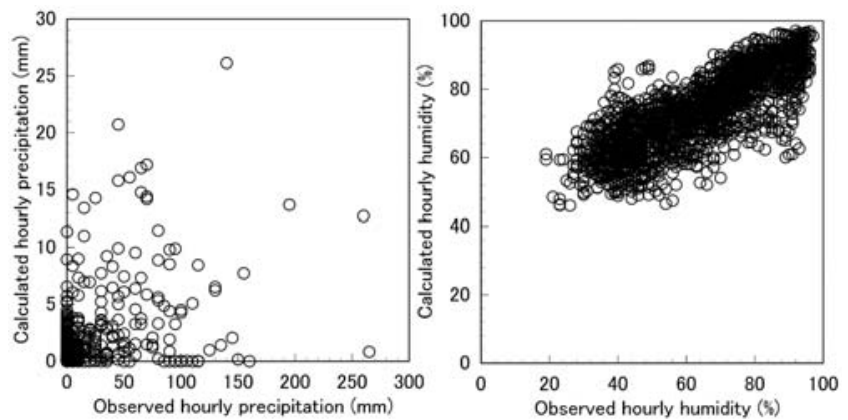

Fig. 1. Relationship between observed and calculated values, derived from a numerical weather prediction model for precipitation and relative humidity, at the Shionomisaki Observatory for 2010 .

Table 1. Output of a multiple regression analysis using SAS software for the four variables from the $K_{\mathrm{s}}$ model.

\begin{tabular}{cccc}
\hline Variables & $\begin{array}{c}\text { Partial regression coefficient of } \\
\text { determination }\end{array}$ & F-value & $\operatorname{Pr}>\mathrm{F}$ \\
\hline$R_{\mathrm{a}}$ & 0.3075 & 1615.51 & $<.0001$ \\
$R$ & 0.0814 & 39.01 & $<.0001$ \\
$\sin h$ & 0.0008 & 25.7 & $<.0001$ \\
$Q$ & 0.0012 & 5 & $<.0001$ \\
\hline
\end{tabular}

Note: $R_{\mathrm{a}}=$ hourly normal extraterrestrial solar radiation $\left(\mathrm{MJ} \mathrm{m}^{-2} \mathrm{~h}^{-1}\right) ; R=$ hourly precipitation $\left(\mathrm{mm} \mathrm{h}^{-1}\right) ; \sin h=$ sine of sun altitude angle; $Q=$ hourly extraterrestrial solar radiation on horizontal surface $\left(\mathrm{MJ} \mathrm{m}^{-2} \mathrm{~h}^{-1}\right)$. 


\subsection{Data}

Hourly global solar radiation was measured by a pyranometer (MS-801; EKO Instruments, Japan), while direct solar radiation was measured by a pyrheliometer (MS-53; EKO Instruments). These solar radiation data were observed throughout 2007 at 14 sites in Japan. Observations at four sites (Sapporo, Tsukuba, Fukuoka, and Ishigakijima) were continued through to 2010. From April 2010, precise observations of hourly direct solar radiation using another pyrheliometer (CHP1; Kipp \& Zonen, The Netherlands) and diffuse solar radiation using another pyranometer (CMP22; Kipp \& Zonen) were carried out at five sites (Sapporo, Tsukuba, Fukuoka, Ishigakijima, and Minamitorishima) by JMA. Observational data for these five sites (Fig. 2) were used for development and validation of the estimation methods presented herein.

Estimation models for $P, K_{\mathrm{ds}}$, and $K_{\mathrm{s}}$ were developed using the least squares method, based on analyzing 10 years (1997-2006) of data from the Shionomisaki Observatory. This observatory is located at central latitudes of Japan, where there is least snow reflection. Data having $\sin h \geq 0.2$ were used for $P, K_{\mathrm{ds}}$, and $K_{\mathrm{s}}$ estimation models, because the ratio of reflected solar radiation was larger at lower sun altitudes. Sun altitudes were computed every 30 min. $R_{\mathrm{d}}$ data were calculated by subtracting $R_{\mathrm{b}}$ from $R_{\mathrm{g}}$. Only data for which $L$ was zero were used for the $K_{\mathrm{s}}$ estimation model (Eq. 12).

The JMA began running an MSM at $10-\mathrm{km}$ resolution in March 2001, for which 18-h time integrations were performed four times daily (Saito et al., 2006). Its resolution was enhanced to $5 \mathrm{~km}$ in March 2006 and run on a 3-hourly basis (eight times daily). The forecast range was extended to 33-h in March 2007. These MSM run extensions were carried out in accordance with initial and boundary conditions consistent with the global spectral model at 20-km resolution (Nakagawa, 2005; JMA, 2007). MSM outputs were generally acquired as grid point

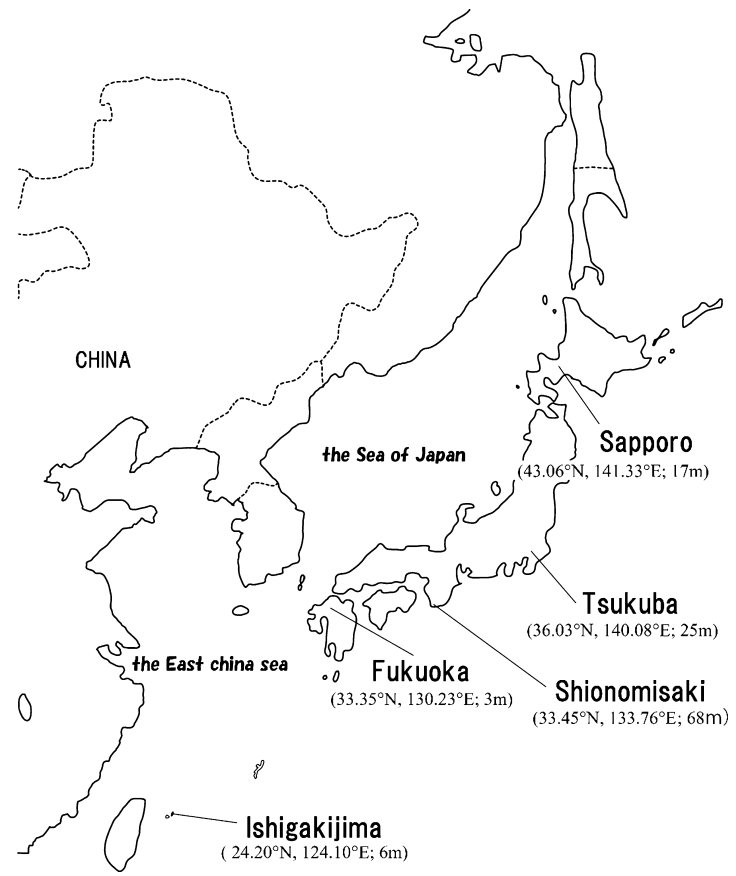

Fig. 2. Locations of meteorological observatories referenced in this study: latitude (degrees), longitude (degrees), and height (m). values, and were used here for model development.

Estimation models for $G P, G K_{\mathrm{ds}}$, and $G K_{\mathrm{s}}$ were developed using Tsukuba Observatory data from 2010 to 2012; this is because solar radiation observations at Shionomisaki Observatory were terminated in 2007. Prediction data ranging from 1 to $6 \mathrm{~h}$ after the initial time (09:00 JST) were used as MSM outputs. Sun altitudes were computed every $30 \mathrm{~min}$. In this study, the MSM gridded outputs nearest to the observatory were used.

\section{Results and Discussion}

\subsection{Estimation methods using observational data}

Coefficient values used for $P$ (Eq. 11), $K_{\mathrm{ds}}$ (Eq. 10), and $K_{\mathrm{s}}$ (Eq. 12) estimation models are shown in Table 2. The accuracy of the estimation models based on observatory data was verified at three sites: Sapporo, Fukuoka, and Ishigakijima. Comparisons between estimated and observed $P$ are shown in Fig. 3 for the 3-year period from 2012 to 2014. The relationship between estimated and observed $R_{\mathrm{b}}$ is shown in Fig. 4 for the same period. Only data with $\sin h \geq 0.1$ were used. Sun altitudes were computed every $30 \mathrm{~min}$. The tendency of estimation errors in both $R_{\mathrm{b}}$ and $P$ were similar for all three sites. For lower values, the estimation errors for $P$ are initially larger, but for higher values, the estimation errors for $P$ become smaller (Fig. 3). The initial lower error values result from less absolute direct radiation at low sun altitudes, while latter errors result from less attenuation of extraterrestrial solar radiation under stronger radiation. Estimation errors for $R_{\mathrm{b}}$ were also larger initially. This produces less absolute error at lower sun altitudes. The largest errors for $R_{\mathrm{b}}$ occur for the middle values in Fig. 4. This reflects estimation errors related to transmittance. Because estimation errors for both $P$ and $R_{\mathrm{b}}$ are related to local atmospheric characteristics rather than regional ones, the trend in estimation errors for both $P$ and $R_{\mathrm{b}}$ were similar at all three sites. RMSEs for direct solar radiation were below $0.3 \mathrm{MJ} \mathrm{m}^{-2} \mathrm{~h}^{-1}$, while the mean bias error (MBE) approached zero. RMSEs for $P$ was around 0.08 for observational data.

A sunshine duration sensor (MS-093; EKO Instruments) within the AMeDAS was used to observe sunshine duration, once direct normal solar radiation exceeded a threshold of 120 $\mathrm{Wm}^{-2}$, consistent with the World Meteorological Organization (WMO) standard. However, direct solar radiation may not be zero for all cases of zero sunshine duration, because duration is not recorded when direct solar radiation is less than $120 \mathrm{Wm}^{-2}$.

Table 2. Values for coefficients used in estimation models based on meteorological observatory data.

\begin{tabular}{cccc}
\hline \multirow{2}{*}{$P$} & $\alpha$ & $\beta$ & $\gamma$ \\
\cline { 2 - 4 } & 0.5792 & -0.08943 & 0.345 \\
\hline \multirow{2}{*}{$K_{\mathrm{ds}}$} & $\mathrm{A}$ & $\mathrm{B}$ & $\mathrm{C}$ \\
\cline { 2 - 4 } & 1.133 & 1.203 & 1.84 \\
\hline \multirow{2}{*}{$K_{\mathrm{s}}$} & $\mathrm{a}$ & $\mathrm{b}$ & $\mathrm{c}$ \\
\cline { 2 - 4 } & -0.00979 & -0.6162 & 3.306 \\
\hline
\end{tabular}

Note: $P=$ hourly atmospheric transmittance; $K_{\mathrm{ds}}=$ dimensionless parameter formulated using $K_{\mathrm{d}}$, a dimensionless parameter for hourly direct solar radiation; $K_{\mathrm{s}}=$ dimensionless parameter for hourly diffuse solar radiation. 

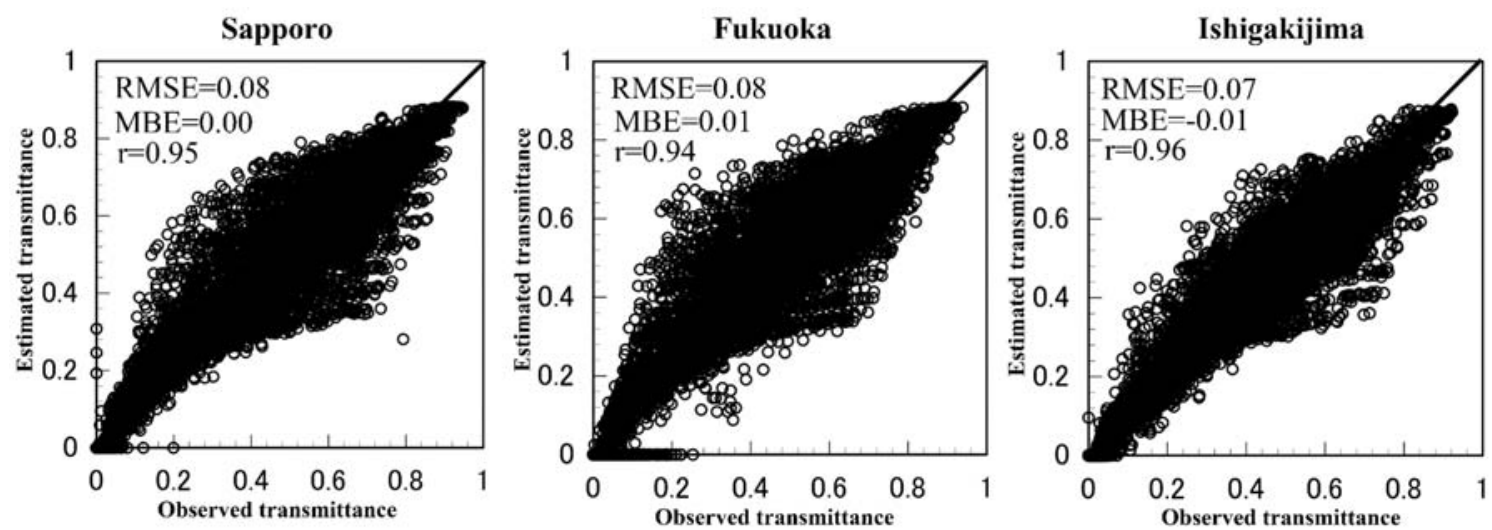

Fig. 3. Correlation between measured and estimated values for hourly solar transmittance, based on data from three meteorological observatories over the 3-year period from 2012 to 2014 (RMSE $=$ root mean square error; $\mathrm{MBE}=$ mean bias error; $\mathrm{r}=$ correlation coefficient).
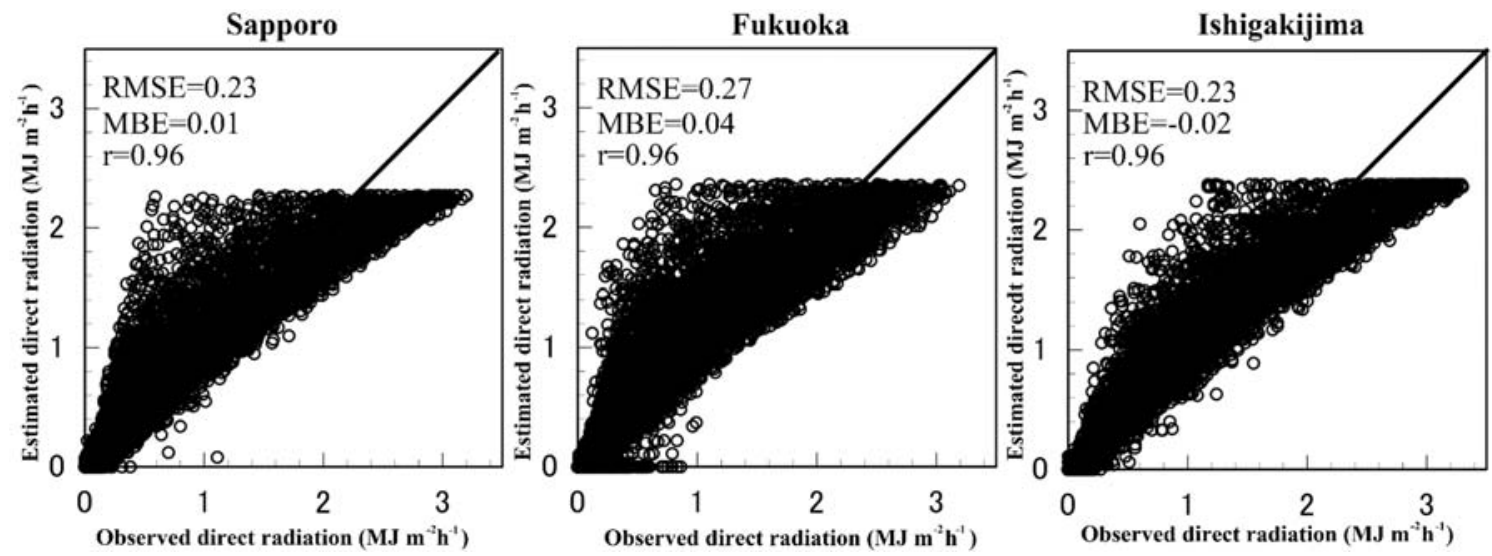

Fig. 4. Correlation between measured and estimated values for hourly direct solar radiation, based on data from three meteorological observatories over the 3-year period from 2012 to 2014 (RMSE = root mean square error; MBE = mean bias error; $r=$ correlation coefficient).

Typically, $80 \%$ of the hourly direct solar radiation data were zero, under the condition of zero sunshine duration; while $99 \%$ of the hourly amount of direct solar radiation data had values less than $0.05 \mathrm{MJ} \mathrm{m}^{-2}$ at Sapporo, Fukuoka, and Ishigakijima observatories during 2014. Direct solar radiation is technically zero, when $L$ is zero.

Estimated and observed $R_{\mathrm{d}}$ values are shown in Fig. 5 for the 3 -year period from 2012 to 2014 . Only data with $\sin h \geq 0.1$ were used. Sun altitudes were computed every $30 \mathrm{~min}$. RMSEs at all sites were approximately $0.3 \mathrm{MJ} \mathrm{m}^{-2} \mathrm{~h}^{-1}$, whereas MBEs were around $0.1 \mathrm{MJ} \mathrm{m}^{-2} \mathrm{~h}^{-1}$. The tendency of errors was similar at all three sites, but was dissimilar to errors generated for estimated direct solar radiation, when solar radiation values were large. This reflects constant atmospheric scattering, even under strong incident radiation. Verification of $R_{\mathrm{d}}$ estimates when $L$ was zero, for the 3-year period from 2012 to 2014, are shown in Table 3. RMSEs improved from 0.59 to $0.25 \mathrm{MJ} \mathrm{m}^{-2} \mathrm{~h}^{-1}$, while the correlation coefficient (r) improved from 0.27 to 0.71 on cloudy or rainy days. Clearly, the new method substantially improved estimation under these conditions.

Table 4 shows RMSE and MBE values for $R_{\mathrm{b}}, R_{\mathrm{d}}$ and $R_{\mathrm{g}}$, estimated using both original and improved estimation methods at various diurnal times. RMSE and MBE values for estimates
Table 3. Root mean square error (RMSE) and coefficient of determination $(r)$ for zero sunshine duration over the 3-year period (2012-2014), based on the new improved method presented in this study (New) and a previous version of this method (Old).

\begin{tabular}{ccc}
\hline Methods & RMSE & r \\
\hline New & 0.25 & 0.71 \\
Old & 0.59 & 0.27 \\
\hline
\end{tabular}

based on the new method showed greater accuracy at all times. RMSE and MBE values for $R_{\mathrm{b}}$ and $R_{\mathrm{d}}$ estimated for three consecutive years are shown in Table 5. Estimation errors were similar over multiple years. Thus, the estimation models developed here appear to be valid throughout Japan, as both RMSE and MBE values were consistent over time.

The 2014 relationship between estimated and observed daily $R_{\mathrm{g}}$ is shown in Fig. 6. Accuracy of the estimation methods used in this study compared favorably with several other methods, including that of Yang et al. (2006) using surface pressure, precipitable water, and ozone layer thickness to estimate daily solar radiation with a RMSE $=1.64 \mathrm{MJ} \mathrm{m}^{-2} \mathrm{~d}^{-1}$; six models using readily available weather data at seven sites to estimate daily 
Table 4. Root mean square error (RMSE; MJ m $\mathrm{m}^{-2}$ ) and mean bias error (MBE; MJ m $\mathrm{m}^{-2}$ ) for direct $\left(R_{\mathrm{b}}\right)$, diffuse $\left(R_{\mathrm{d}}\right)$, and global $\left(R_{\mathrm{g}}\right)$ solar radiation over the 3-year period (2012-2014) at three sites (listed separately); old $R_{\mathrm{b}}$, old $R_{\mathrm{d}}$, and old $R_{\mathrm{g}}$ represent the same radiation estimates from a previous version of this method.

Sapporo

\begin{tabular}{ccccccccccccc}
\hline Time & $\begin{array}{c}R_{\mathrm{b}} \\
\text { RMSE }\end{array}$ & $\begin{array}{c}R_{\mathrm{b}} \\
\text { MBE }\end{array}$ & $\begin{array}{c}\text { old } R_{\mathrm{b}} \\
\text { RMSE }\end{array}$ & $\begin{array}{c}\text { old } R_{\mathrm{b}} \\
\text { MBE }\end{array}$ & $\begin{array}{c}R_{\mathrm{d}} \\
\text { RMSE }\end{array}$ & $\begin{array}{c}R_{\mathrm{d}} \\
\text { MBE }\end{array}$ & $\begin{array}{c}\text { old } R_{\mathrm{d}} \\
\text { RMSE }\end{array}$ & $\begin{array}{c}\text { old } R_{\mathrm{d}} \\
\text { MBE }\end{array}$ & $\begin{array}{c}R_{\mathrm{g}} \\
\text { RMSE }\end{array}$ & $\begin{array}{c}R_{\mathrm{g}} \\
\text { MBE }\end{array}$ & $\begin{array}{c}\text { old } R_{\mathrm{g}} \\
\text { RMSE }\end{array}$ & $\begin{array}{c}\text { old } R_{\mathrm{g}} \\
\text { MBE }\end{array}$ \\
\hline 7 & 0.19 & 0.07 & 0.17 & -0.08 & 0.23 & 0.15 & 0.57 & 0.48 & 0.34 & 0.22 & 0.50 & 0.40 \\
8 & 0.22 & 0.06 & 0.25 & -0.11 & 0.26 & 0.16 & 0.58 & 0.38 & 0.33 & 0.22 & 0.49 & 0.27 \\
9 & 0.26 & 0.05 & 0.32 & -0.13 & 0.28 & 0.14 & 0.65 & 0.33 & 0.33 & 0.19 & 0.55 & 0.20 \\
10 & 0.29 & 0.01 & 0.37 & -0.15 & 0.30 & 0.10 & 0.66 & 0.28 & 0.29 & 0.11 & 0.56 & 0.13 \\
11 & 0.32 & -0.01 & 0.40 & -0.14 & 0.33 & 0.06 & 0.67 & 0.20 & 0.29 & 0.04 & 0.59 & 0.06 \\
12 & 0.32 & -0.03 & 0.40 & -0.16 & 0.34 & 0.02 & 0.65 & 0.16 & 0.29 & 0.00 & 0.57 & 0.00 \\
13 & 0.27 & -0.02 & 0.38 & -0.19 & 0.31 & -0.02 & 0.60 & 0.13 & 0.26 & -0.04 & 0.52 & -0.05 \\
14 & 0.22 & -0.02 & 0.36 & -0.20 & 0.28 & -0.05 & 0.50 & 0.13 & 0.25 & -0.07 & 0.41 & -0.06 \\
15 & 0.17 & -0.01 & 0.33 & -0.19 & 0.26 & -0.07 & 0.41 & 0.12 & 0.23 & -0.08 & 0.33 & -0.07 \\
16 & 0.12 & 0.00 & 0.30 & -0.19 & 0.21 & -0.08 & 0.32 & 0.16 & 0.20 & -0.08 & 0.28 & -0.02 \\
17 & 0.08 & -0.01 & 0.22 & -0.15 & 0.19 & -0.09 & 0.19 & 0.05 & 0.19 & -0.09 & 0.22 & -0.09 \\
18 & 0.04 & -0.02 & 0.11 & -0.08 & 0.18 & -0.12 & 0.15 & -0.10 & 0.20 & -0.14 & 0.21 & -0.18 \\
\hline
\end{tabular}

Fukuoka

\begin{tabular}{ccccccccccccc}
\hline Time & $\begin{array}{c}R_{\mathrm{b}} \\
\text { RMSE }\end{array}$ & $\begin{array}{c}R_{\mathrm{b}} \\
\text { MBE }\end{array}$ & $\begin{array}{c}\text { old } R_{\mathrm{b}} \\
\text { RMSE }\end{array}$ & $\begin{array}{c}\text { old } R_{\mathrm{b}} \\
\text { MBE }\end{array}$ & $\begin{array}{c}R_{\mathrm{d}} \\
\text { RMSE }\end{array}$ & $\begin{array}{c}R_{\mathrm{d}} \\
\text { MBE }\end{array}$ & $\begin{array}{c}\text { old } R_{\mathrm{d}} \\
\text { RMSE }\end{array}$ & $\begin{array}{c}\text { old } R_{\mathrm{d}} \\
\text { MBE }\end{array}$ & $\begin{array}{c}R_{\mathrm{g}} \\
\text { RMSE }\end{array}$ & $\begin{array}{c}R_{\mathrm{g}} \\
\text { MBE }\end{array}$ & $\begin{array}{c}\text { old } R_{\mathrm{g}} \\
\text { RMSE }\end{array}$ & $\begin{array}{c}\text { old } R_{\mathrm{g}} \\
\text { MBE }\end{array}$ \\
\hline 7 & 0.16 & 0.05 & 0.07 & -0.03 & 0.23 & 0.14 & 0.56 & 0.52 & 0.33 & 0.20 & 0.53 & 0.49 \\
8 & 0.24 & 0.11 & 0.14 & -0.05 & 0.24 & 0.16 & 0.58 & 0.45 & 0.40 & 0.27 & 0.54 & 0.41 \\
9 & 0.27 & 0.11 & 0.25 & -0.08 & 0.29 & 0.20 & 0.66 & 0.42 & 0.42 & 0.31 & 0.60 & 0.34 \\
10 & 0.30 & 0.08 & 0.33 & -0.08 & 0.32 & 0.19 & 0.68 & 0.34 & 0.39 & 0.26 & 0.64 & 0.26 \\
11 & 0.35 & 0.04 & 0.41 & -0.06 & 0.34 & 0.16 & 0.70 & 0.23 & 0.37 & 0.20 & 0.69 & 0.17 \\
12 & 0.36 & 0.00 & 0.43 & -0.07 & 0.35 & 0.11 & 0.69 & 0.16 & 0.36 & 0.12 & 0.68 & 0.09 \\
13 & 0.32 & -0.01 & 0.41 & -0.12 & 0.33 & 0.08 & 0.68 & 0.13 & 0.32 & 0.07 & 0.65 & 0.01 \\
14 & 0.29 & 0.01 & 0.38 & -0.16 & 0.31 & 0.02 & 0.61 & 0.15 & 0.28 & 0.04 & 0.55 & -0.01 \\
15 & 0.24 & 0.04 & 0.35 & -0.19 & 0.27 & -0.03 & 0.46 & 0.17 & 0.22 & 0.00 & 0.38 & -0.02 \\
16 & 0.18 & 0.04 & 0.28 & -0.17 & 0.25 & -0.09 & 0.32 & 0.14 & 0.20 & -0.05 & 0.29 & -0.03 \\
17 & 0.12 & 0.03 & 0.22 & -0.14 & 0.25 & -0.12 & 0.25 & 0.07 & 0.22 & -0.09 & 0.28 & -0.07 \\
18 & 0.05 & 0.00 & 0.12 & -0.07 & 0.23 & -0.14 & 0.18 & -0.09 & 0.24 & -0.14 & 0.24 & -0.16 \\
\hline
\end{tabular}

Ishigakijima

\begin{tabular}{ccccccccccccc}
\hline Time & $\begin{array}{c}R_{\mathrm{b}} \\
\text { RMSE }\end{array}$ & $\begin{array}{c}R_{\mathrm{b}} \\
\text { MBE }\end{array}$ & $\begin{array}{c}\text { old } R_{\mathrm{b}} \\
\text { RMSE }\end{array}$ & $\begin{array}{c}\text { old } R_{\mathrm{b}} \\
\text { MBE }\end{array}$ & $\begin{array}{c}R_{\mathrm{d}} \\
\text { RMSE }\end{array}$ & $\begin{array}{c}R_{\mathrm{d}} \\
\text { MBE }\end{array}$ & $\begin{array}{c}\text { old } R_{\mathrm{d}} \\
\text { RMSE }\end{array}$ & $\begin{array}{c}\text { old } R_{\mathrm{d}} \\
\text { MBE }\end{array}$ & $\begin{array}{c}R_{\mathrm{g}} \\
\text { RMSE }\end{array}$ & $\begin{array}{c}R_{\mathrm{g}} \\
\text { MBE }\end{array}$ & $\begin{array}{c}\text { old } R_{\mathrm{g}} \\
\text { RMSE }\end{array}$ & $\begin{array}{c}\text { old } R_{\mathrm{g}} \\
\text { MBE }\end{array}$ \\
\hline 7 & 0.02 & -0.01 & 0.05 & -0.03 & 0.22 & 0.11 & 0.44 & 0.41 & 0.22 & 0.11 & 0.41 & 0.39 \\
8 & 0.16 & 0.06 & 0.12 & -0.06 & 0.29 & 0.20 & 0.63 & 0.60 & 0.39 & 0.26 & 0.56 & 0.54 \\
9 & 0.20 & 0.09 & 0.21 & -0.11 & 0.33 & 0.24 & 0.71 & 0.55 & 0.43 & 0.33 & 0.61 & 0.44 \\
10 & 0.22 & 0.03 & 0.26 & -0.12 & 0.36 & 0.24 & 0.76 & 0.42 & 0.39 & 0.27 & 0.66 & 0.30 \\
11 & 0.27 & -0.05 & 0.31 & -0.11 & 0.39 & 0.17 & 0.78 & 0.17 & 0.34 & 0.12 & 0.73 & 0.06 \\
12 & 0.33 & -0.09 & 0.35 & -0.09 & 0.40 & 0.12 & 0.79 & 0.10 & 0.33 & 0.04 & 0.76 & 0.01 \\
13 & 0.34 & -0.10 & 0.36 & -0.12 & 0.40 & 0.08 & 0.80 & 0.03 & 0.32 & -0.02 & 0.75 & -0.09 \\
14 & 0.29 & -0.07 & 0.36 & -0.17 & 0.37 & 0.03 & 0.73 & 0.04 & 0.31 & -0.04 & 0.64 & -0.13 \\
15 & 0.22 & -0.04 & 0.36 & -0.22 & 0.32 & -0.02 & 0.63 & 0.15 & 0.27 & -0.05 & 0.52 & -0.06 \\
16 & 0.17 & -0.01 & 0.36 & -0.23 & 0.27 & -0.06 & 0.46 & 0.18 & 0.24 & -0.07 & 0.37 & -0.05 \\
17 & 0.10 & -0.02 & 0.28 & -0.18 & 0.23 & -0.10 & 0.26 & 0.08 & 0.24 & -0.12 & 0.26 & -0.10 \\
18 & 0.08 & -0.04 & 0.20 & -0.14 & 0.22 & -0.14 & 0.19 & -0.07 & 0.26 & -0.18 & 0.26 & -0.20 \\
\hline
\end{tabular}


Table 5. Root mean square error (RMSE; $M J \mathrm{~m}^{-2} \mathrm{~h}^{-1}$ ) and mean bias error (MBE; $\mathrm{MJ} \mathrm{m}^{-2} \mathrm{~h}^{-1}$ ) for direct and diffuse solar radiation at three sites (listed separately) for 3-year period (2012-2014).

Sapporo

\begin{tabular}{|c|c|c|c|c|}
\hline \multirow{2}{*}{ Year } & \multicolumn{2}{|c|}{ Direct } & \multicolumn{2}{|c|}{ Diffuse } \\
\hline & RMSE & MBE & RMSE & MBE \\
\hline 2012 & 0.22 & 0.01 & 0.27 & 0.02 \\
\hline 2013 & 0.23 & 0.01 & 0.28 & 0.04 \\
\hline 2014 & 0.26 & 0.01 & 0.27 & 0.05 \\
\hline
\end{tabular}

Fukuoka

\begin{tabular}{ccccc}
\hline Year & Direct & \multicolumn{2}{c}{ Diffuse } \\
& RMSE & MBE & RMSE & MBE \\
\hline 2012 & 0.27 & 0.04 & 0.29 & 0.07 \\
2013 & 0.26 & 0.04 & 0.29 & 0.08 \\
2014 & 0.26 & 0.05 & 0.28 & 0.06 \\
\hline
\end{tabular}

Ishigakijima

\begin{tabular}{|c|c|c|c|c|}
\hline \multirow{2}{*}{ Year } & \multicolumn{2}{|c|}{ Direct } & \multicolumn{2}{|c|}{ Diffuse } \\
\hline & RMSE & $\mathrm{MBE}$ & RMSE & MBE \\
\hline 2012 & 0.21 & -0.02 & 0.33 & 0.07 \\
\hline 2013 & 0.23 & -0.04 & 0.34 & 0.1 \\
\hline 2014 & 0.25 & -0.01 & 0.32 & 0.08 \\
\hline
\end{tabular}
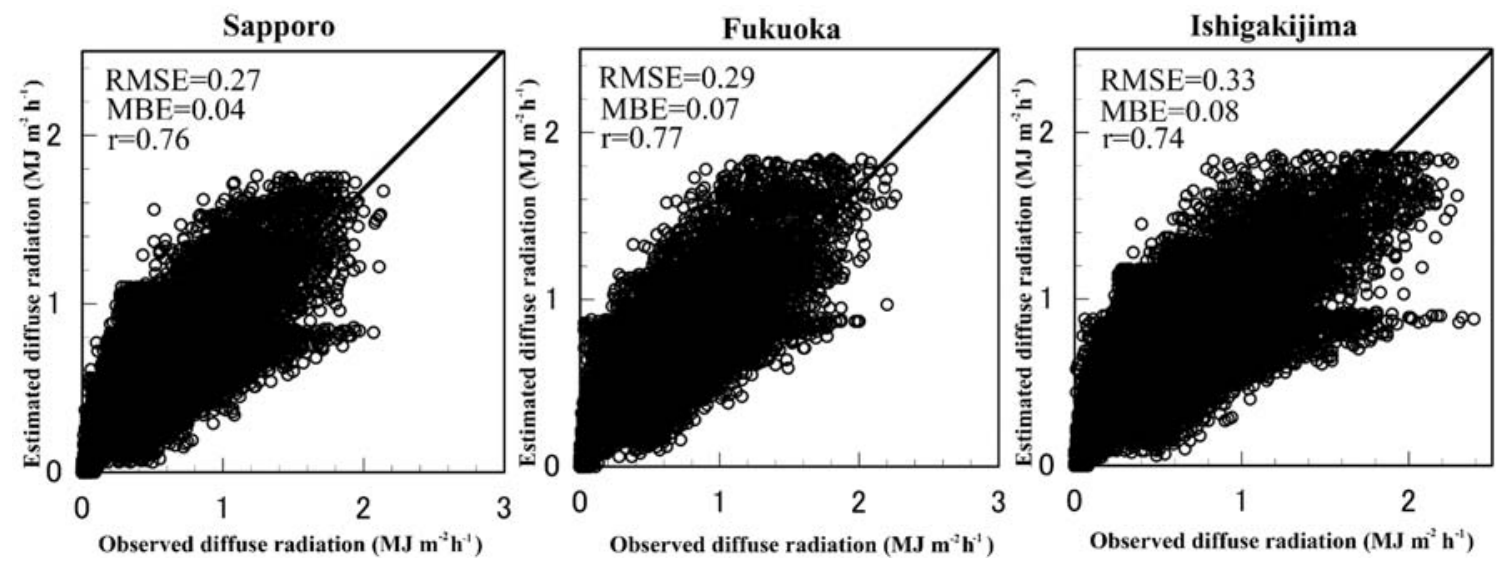

Fig. 5. Correlation between measured and estimated values for hourly diffuse solar radiation, based on data from three meteorological observatories over the 3-year period from 2012 to 2014. (RMSE = root mean square error; $\mathrm{MBE}=$ mean bias error; $\mathrm{r}=$ correlation coefficient)
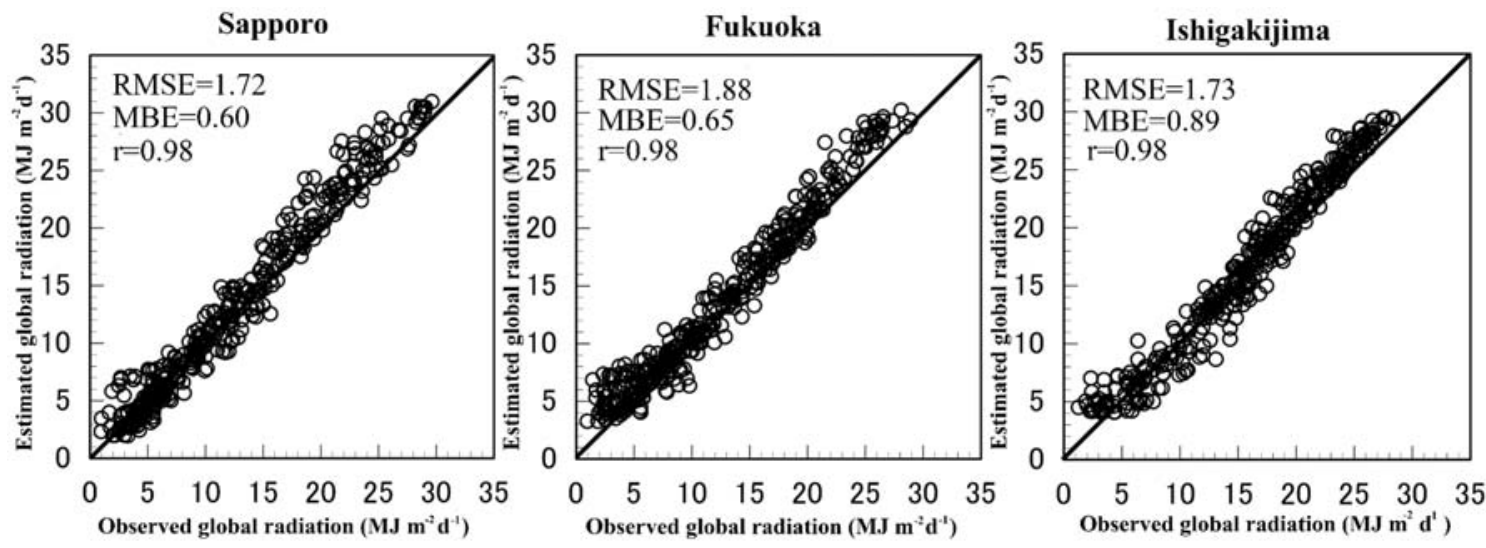

Fig. 6. Correlation between measured and estimated values for daily global solar radiation, based on data from three meteorological observatories for 2014. (RMSE $=$ root mean square error; $\mathrm{MBE}=$ mean bias error; $r=$ correlation coefficient) 
solar radiation having a RMSE $=3.24-3.66 \mathrm{MJ} \mathrm{m}^{-2} \mathrm{~d}^{-1}($ Abraha and Savage, 2008); a calibrated Angstrom-Prescott (A-P) model, being the best model of nine based on sunshine and temperature at eight Canadian sites used to estimate daily solar radiation, with a RMSE $=0.8-8 \mathrm{MJ} \mathrm{m}^{-2} \mathrm{~d}^{-1}$ and an average of $4.2 \mathrm{MJ} \mathrm{m}^{-2} \mathrm{~d}^{-1}$ (Aladenora and Madramootoo, 2014). Although the Environmental \& Water Resources Institute (EWRI) of the American Society of Civil Engineers (ASCE) estimation model for clearsky solar radiation predicted solar radiation on slopes with superior accuracy (RMSE $<0.1 \mathrm{MJ} \mathrm{m}^{-2} \mathrm{~h}^{-1}$; Allen et al., 2006), this model requires values for actual vapor pressure, the equivalent depth of precipitable water, and a turbidity coefficient, which are generally difficult to acquire. Our results are superior to the A-P model recommended by the Food and Agricultural Organization of the United Nations (FAO) -56 guidelines for computing crop water requirements (Allen et al., 1998; Table 6). Clearly, adequate data for solar radiation in complex terrains can be estimated using the method developed herein for $R_{\mathrm{b}}$ and $R_{\mathrm{d}}$.

Because variables for the $P, K_{\mathrm{ds}}$, and $K_{\mathrm{s}}$ estimation models were not derived based on theoretical concepts, the models developed herein cannot be applied worldwide. Generally, models based on physical equations for solar radiation are more universally applicable and scientifically sound than regionally restricted statistical models. Badescu et al. (2013) reported that complex models need a precise description of the state of the atmosphere, as input. Thus, such models provide much better results than simple models, when the average irradiance is computed at short time intervals, involving minutes or seconds. However, the method presented herein is useful from a practical perspective, because statistical techniques play a role in

Table 6. Root mean square error $\left(\mathrm{MJ} \mathrm{m}^{-2} \mathrm{~d}^{-1}\right)$ for daily global solar radiation at three sites for 2014, estimated using the Angstrom-Prescott (A-P) model; Food and Agricultural Organization of the United Nations (FAO) -recommended coefficients $(\mathrm{a}=0.25, \mathrm{~b}=0.50)$ were used in this method.

\begin{tabular}{cc}
\hline Sites & A-P model \\
\hline Sapporo & 2.00 \\
Fukuoka & 2.80 \\
Ishigakijima & 2.26 \\
\hline
\end{tabular}

simulating data using restricted factors. In this study, the objective was not to define elements influencing incident solar radiation at the surface, but rather to assess practical solar radiation data for a specific region. Furthermore, this method does not require special instruments; therefore, it can be conveniently transferred to other regions, making use of meteorological observation networks that exist worldwide.

\subsection{Estimation methods using a numerical weather predic- tion model outputs}

Coefficients for $G P, \mathrm{G} K_{\mathrm{ds}}$, and $\mathrm{G} K_{\mathrm{s}}$ estimation models are shown in Table 7. Comparisons between estimation and observation data for both $R_{\mathrm{b}}$ and $R_{\mathrm{d}}$ are shown in Fig. 7 and 8 for the 2-year period from 2013 to 2014. These plots show values for the time interval 10:00-15:00 JST. Estimations of $R_{\mathrm{b}}$ at Sapporo and Fukuoka are better than at Ishigakijima, because of better correlation between variables. Estimations of $R_{\mathrm{d}}$ at Sapporo are better than at Fukuoka and Ishigakijima, because of lower MBEs. These differences in error may reflect the accuracy of the MSM outputs, given that local effects on errors were not detected in estimations based on observational data. Sapporo is situated in a subarctic region and has a cooler and more stable atmosphere than Ishigakijima, which is situated within a subtropical region, or Fukuoka, which is situated in a monsoon region. In this context, estimates of $C L$ and $R H$ may have been better at Sapporo, because of better correlation between estimated and observed $P$ values (Fig. 9) over this period. Clearly, at this stage, it is difficult to use the estimated hourly data for assessment of solar radiation with high resolution, because estimation errors are large and correlations are poor. Nevertheless, daily data may provide an alternative to such assessment. The 6-hourly $R_{\mathrm{g}}$ data (Fig. 10) appear to show a more favorable correlation. This numerical method will become a more viable alternative to current methods of estimation, as the estimation accuracy of numerical weather models improves.

\section{Conclusions}

A convenient method was developed for estimating hourly direct and diffuse solar radiation on a horizontal surface, using low-cost public data from an automated meteorological observatory. Hourly direct and diffuse solar radiation estimated using the proposed method will be useful throughout Japan to

Table 7. Coefficients for the estimation model based on output from a numerical weather prediction model.

\begin{tabular}{ccccc}
\hline \multirow{2}{*}{$G P$} & $\mathrm{G}_{\alpha}$ & $\mathrm{G}_{\beta}$ & $\mathrm{G}_{\gamma}$ & $\mathrm{G}_{\delta}$ \\
\cline { 2 - 4 } & -0.04389 & -0.005940 & -0.005010 & 1.063 \\
\cline { 2 - 4 }$G K_{d s}$ & $\mathrm{G}_{\mathrm{A}}$ & $\mathrm{G}_{\mathrm{B}}$ & $\mathrm{G}_{\mathrm{C}}$ \\
\hline \multirow{2}{*}{$G K_{S}$} & 0.8137 & 1.098 & 1.927 \\
\cline { 2 - 4 } & $\mathrm{G}_{\mathrm{a}}$ & $\mathrm{G}_{\mathrm{b}}$ & $\mathrm{G}_{\mathrm{c}}$ \\
\hline
\end{tabular}

Note: $G P=$ hourly atmospheric transmittance used in the estimation model based on weather prediction model outputs; $G K_{\mathrm{ds}}=$ dimensionless parameter formulated using $G K_{\mathrm{d}}$, a dimensionless parameter for hourly direct solar radiation used in the estimation model based on weather prediction model outputs; $G K_{\mathrm{s}}=$ dimensionless parameter for hourly diffuse solar radiation used in the estimation model based on weather prediction model outputs; $G_{A}$ to $G_{C} ; G_{a}$ to $G_{c}$ and $G_{\alpha}$ to $G_{\delta}$ are constants. 

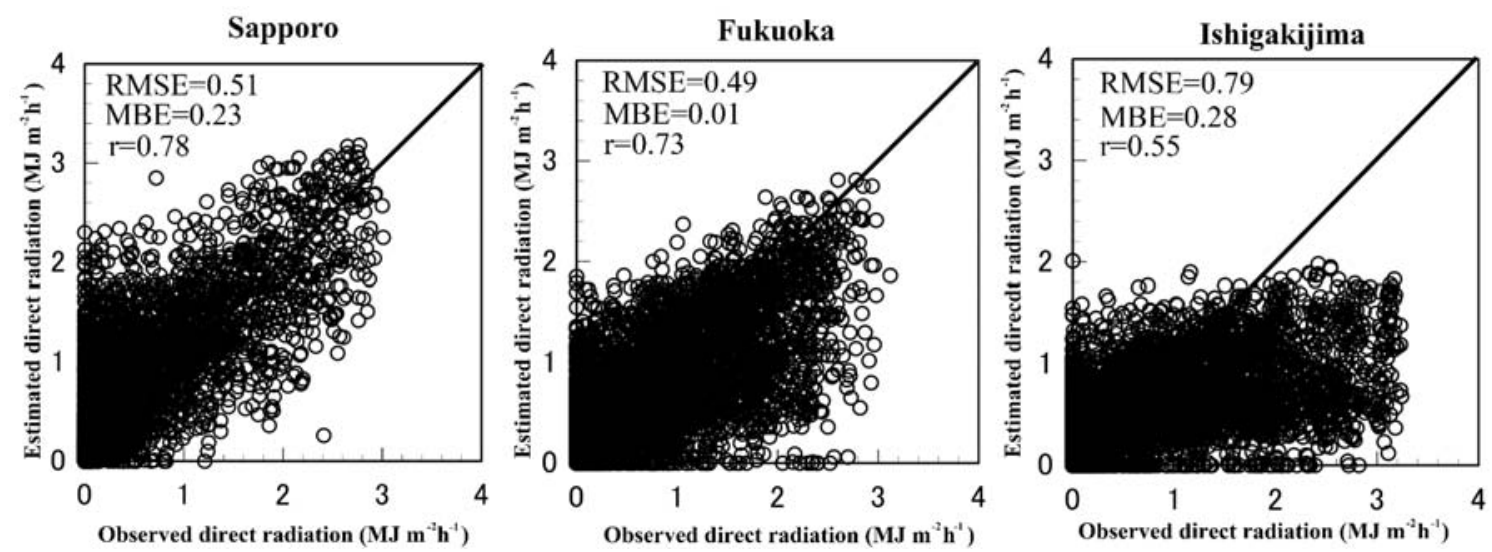

Fig. 7. Correlation between measured and estimated values for hourly direct solar radiation, derived from mesoscale numerical model output for three meteorological observatories over the 2-year period from 2013 to 2014 (RMSE = root mean square error; MBE $=$ mean bias error; $r=$ correlation coefficient).
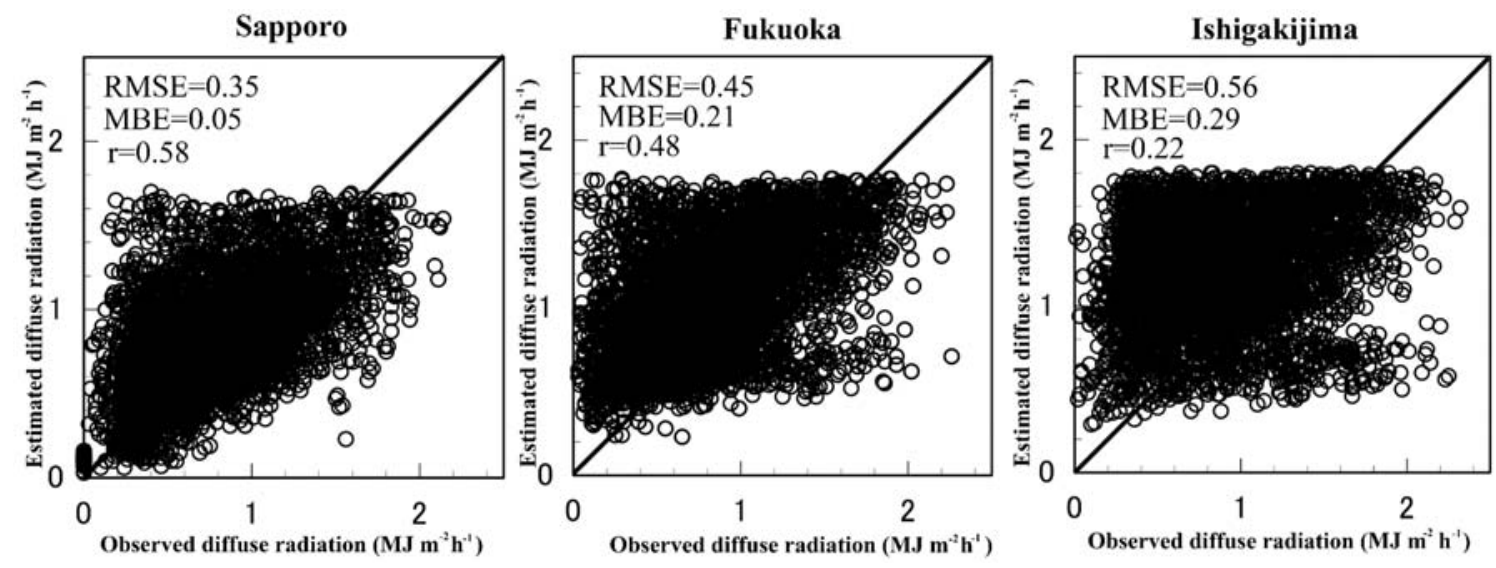

Fig. 8. Correlation between measured and estimated values for hourly diffuse solar radiation, derived from mesoscale numerical model output for three meteorological observatories over the 2-year period from 2013 to 2014 (RMSE = root mean square error; $\mathrm{MBE}=\mathrm{mean}$ bias error; $r=$ correlation coefficient).
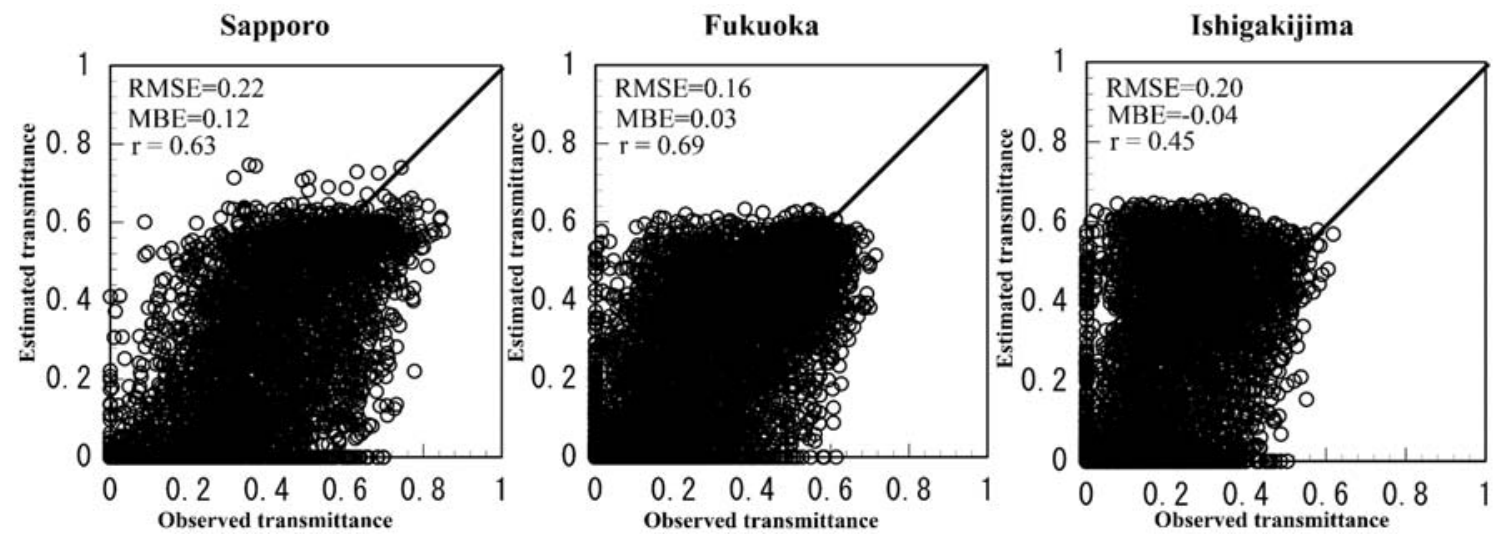

Fig. 9. Correlation between measured and estimated values for hourly solar transmittance, derived from mesoscale numerical model output $(\mathrm{RMSE}=$ root mean square error; $\mathrm{MBE}=$ mean bias error; $\mathrm{r}=$ correlation coefficient $)$ for three meteorological observatories over the 2-year period from 2013 to 2014. 

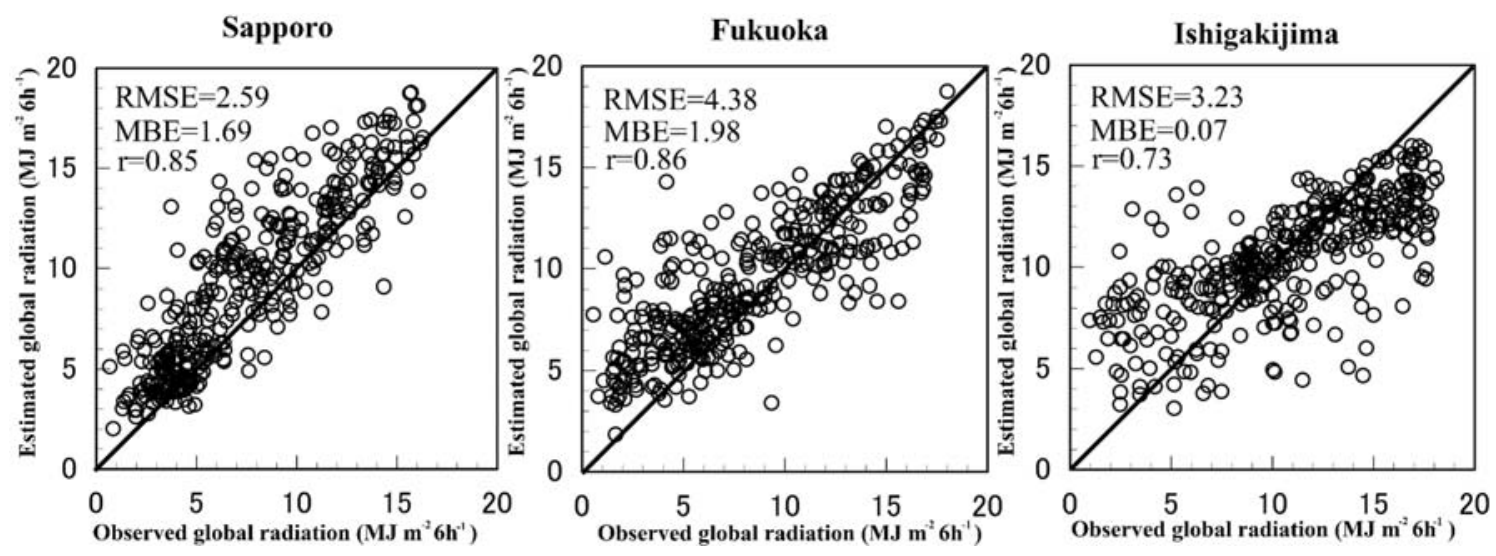

Fig. 10. Correlation between measured and estimated values for 6-h global solar radiation, derived from mesoscale numerical model output for three meteorological observatories for 2014.

facilitate better agricultural crop management. In addition, outputs from a numerical weather prediction model were used to estimate solar radiation in regions lacking meteorological observatories. This method had large estimation errors, caused by model bias, rather than local site factors. At present, it is not feasible to use estimated hourly data generated in this way. However, this approach shows potential, and will improve in accuracy, as numerical weather prediction models are updated.

Clients are willing to pay a fee for agrometeorological information in both developed and developing countries (Weiss et al., 2000). Agricultural bulletins based on meteorological data have been implemented in many countries, and are published by the World AgroMeteorological Information Service (WAMIS; http://wamis.org/). Furthermore, farmers would pay a fee, if such information resulted in greater commercial success. Current meteorological information is not always profitable to farmers, especially those in hilly or mountainous areas. However, precise meteorological data are necessary to generate profit, as they facilitate high-quality production based on precise cultivation management. Such data also need to be available at low cost. Although observational data from automated instruments possess characteristics of precise meteorological data, there are longterm costs to ensure their accuracy. Thus, the approach taken here is to explore a more practical way to provide such information, based on estimates generated from data from automated observatories. Here, it was shown that low-cost reliable data could be generated from observational data using statistical estimation techniques. Such methods provide scope for many agricultural applications, including data required for precise cultivation management.

\section{Acknowledgments}

This work was supported by the Council for Science, Technology and Innovation (CSTI), Cross-ministerial Strategic Innovation Promotion Program (SIP), "Technologies for creating next-generation agriculture, forestry and fisheries" (funding agency: Bio-oriented Technology Research Advancement Institution, NARO). Data from AMeDAS meteorological observatories and the MSM were provided by the Agriculture, Forestry, and Fisheries Research Information Center. SAS computer software used for the least-square methods and stepwise-regression analysis was provided by the Computer Center for Agriculture, Forestry, and Fisheries Research, Ministry of Agriculture, Forestry and Fisheries, Japan. Mr. Nakamigawa of the Japan Meteorological Agency provided valuable advice on observational data for direct and diffuse solar radiation from the three meteorological observatories.

\section{References}

Abraha GM, Savage JM, 2008: Comparison of estimates of daily solar radiation from air temperature range for application in crop simulations. Agricultural and Forest Meteorology 148, 401-416.

Aladenora AA, Madramootoo AC, 2014: Evaluation of solar radiation estimation methods for reference evapotranspiration estimation in Canada. Theoretical and Applied Climatology 118, 377-385.

Allen RG, Pereira LS, Raes D, Smith M, 1998: Crop Evapotranspiration: Guidelines for computing Crop Requirements, Irrigation and Drainage Paper No. 56. FAO, Rome.

Allen RG, Trezza R, Tasumi M, 2006: Analytical integrated functions for daily solar radiation on slopes. Agricultural and Forest Meteorology 139, 55-73.

Badescu V, Gueymard AC, Cheval S, Oprea C, Baciu M, Dumitrescu A, Iacobescu F, 2013: Accuracy and sensitivity analysis for 54 models of computing hourly diffuse solar irradiation on clear sky. Theoretical and Applied Climatology 111, 379-399.

Bird ER, Hulstrom LR, 1981: A simplified clear sky model for direct and diffuse insolation on horizontal surfaces. Technical Report No. SERI/TR-642-761, Golden, CO: Solar Energy Research Institute:

Blennow K, Persson P, 1998: Modelling local-scale frost variations using mobile temperature measurements with a GIS. Agricultural and Forest Meteorology 89, 59-71.

Bugler JW, 1977: The determination of hourly insolation on an inclined plane using a diffuse irradiance model based on hourly measured global horizontal insolation. Solar Energy $\mathbf{9}$, 477-491. 
Butt N, New M, Malhi Y, Costa ACL, Oliveria P, Silva-Espejo JE, 2010: Diffuse radiation and cloud fraction relationships in two contrasting Amazonia rainforest sites. Agricultural and Forest Meteorology 150, 361-368.

Castelli M, Stock1 R, Zard D, Tetslaff A, Wagner JE, Belluardo G, Zebisch M, Petitta M, 2014: The HelioMont method for assessing solar irradiance over complex terrain: Validation and improvements. Remote Sensing Environment 152, 603-613.

Cohen S, Fuchs M, 1987: The distribution of leaf area, radiation, photosynthesis and transpiration in a shamouti orange hedgerow orchard part I. Leaf and radiation. Agricultural and Forest Meteorology 40, 123-144.

Daly C, Smith JW, Smith JI, 2007: High-Resolution Spatial Modeling of Daily Weather elements for a catchment in the Oregon cascade mountains, United States. Journal of Applied Meteorology and Climatology 46, 1565-1586.

Erbs DG, Klein SA, Duffied JA, 1982: Estimation of the diffuse radiation fraction for hourly, daily and monthly average global radiation. Solar Energy 28 (4), 293-302.

Evans TP, Winterhalder B, 2000: Modified solar insolation as an agromic factor in terraced environments. Land Degradation \& Development 11, 273-287.

Flint A, Childs SW, 1987: Calculation of solar radiation in mountainous terrain. Agricultural and Forest Meteorology 40, 233-249.

Gueymard CA, 2003: Direct solar transmittance and irradiance predictions with broadband models. Part I: detailed theoretical performance assessment. Solar Energy 74, 355-379.

Holden AZ, Abatzoglor TJ, Luce HC, Baggett SL, 2011: Empirical downscaling of daily minimum air temperature at very fine resolutions in complex terrain. Agricultural and Forest Meteorology 151, 1066-1073.

Japan Meteorological Agency, 2007: Outline of the operational numerical weather prediction at the Japan Meteorological Agency. Appendix to WMO Numerical weather prediction progress report: http://www.jma.go.jp/jma/jma-eng/jma-center/ nwp/outline-nwp/index.htm

Kurose Y, Nagata K, Ohba K, Maruyama A, 1999: Estimation of potential solar radiation using $50 \mathrm{~m}$ grid digital terrain model. Journal of Agricultural Meteorology 55 (4), 315-322. (in Japanese with English abstract).
Michael RL, 1999: Estimating the diffuse component from daily and monthly measurements of global radiation. Agricultural and Forest Meteorology 95, 169-185.

Nakagawa M, 2005: Precipitation forecasts by a high resolution global model at JMA. BMRC research report 111, 127-130.

Reindl DT, Beckman WA, Duffie JA, 1990a: Diffuse fraction correlations. Solar Energy 45 (1), 1-7.

Reindl DT, Beckman WA, Duffie JA, 1990b: Evaluation of hourly tilted surface radiation models. Solar Energy 45 (1), 9-17.

Saito K, Fujita T, Yamada Y, Ishida J, Kmagai Y, Aranami K, Ohmori S, Nagasawa R, Kumagai S, Muroi C, Kato T, Eito H, Yamazaki Y, 2006. The Operational JMA Nonhydrostatic Mesoscale Model. Monthly Weather Review 134, 1266-1298.

Shibata K, Uchijima Z, 1987: Distribution and Measurements of Solar energy, in: Seino H, Climatological calculation of solar energy. Gakkaishuppan Center, Tokyo, pp. 128 (in Japanese).

Swift LW, Knoerr KR, 1973: Estimating solar radiation on mountain slopes. Agricultural Meteorology 12, 329-336.

Tian YQ, Davies-Colley RJ, Gong P, Thorrold BW, 2001: Estimating solar radiation on slopes of arbitrary aspect. Agricultural and Forest Meteorology 109, 67-74.

Ueyama H, 2005: Estimating hourly direct and diffuse solar radiation for the compilation of solar radiation distribution maps. Journal of Agricultural Meteorlogy 61(4), 207-216.

Ueyama H, 2008: The utilization of mesh meteorological data maps for agricultural activity in hilly and mountainous area. Bull National Agricultural Research center for Western Region 7, 145-207. (in Japanese with English abstract).

Watanabe T, Urano Y, Hayashi T, 1983: Procedures for separating direct and diffuse insolation on a horizontal surface and prediction of insolation on tilted surfaces. Transactions of the Architectural Institute of Japan 330, 96-108 (in Japanese with English abstract).

Weiss A, Crowder LV, Bernardi M, 2000: Communicating agrometeorological information to farming communities. Agricultural and Forest Meteorology 103, 185-196.

Yang K, Koike T, Ye B, 2006: Improving estimation of hourly, daily, and monthly solar radiation by importing global data sets. Agricultural and Forest Meteorology 137, 43-55. 